\title{
DISTRIBUIÇÃO DA UMIDADE DO SOLO NUM SISTEMA IRRIGADO POR GOTEJAMENTO SUPERFICIAL COM DIFERENTES INCLINAÇÕES DO TERRENO
}

\author{
Aluízio Antônio Fernandes da Silva ${ }^{1}$, José Antonio Rodrigues de Souza ${ }^{2}$, Wanderbeth Belchior de Carvalho ${ }^{3}$, Rafael \\ Barcelos Mendonça ${ }^{4}$, Débora Astoni Moreira ${ }^{5}$
}

\begin{abstract}
RESUMO
Informações da geometria do bulbo molhado são importantes para o dimensionamento e o manejo de projetos de irrigação por gotejamento. Existem diversos estudos sobre as dimensões e características do bulbo úmido associando vazões, tempos de aplicação e tipos de solo, todavia, a literatura ainda carece de fontes quanto ao comportamento da região irrigada em terrenos com diferentes declividades. Assim, objetivou-se neste estudo avaliar as dimensões e características do bulbo molhado na irrigação por gotejamento superficial em função da vazão do emissor e da inclinação do terreno. O experimento foi conduzido no Instituto Federal Goiano - Câmpus Urutaí, em Urutaí, GO. No estudo foram adotadas três vazões $\left(4,5\right.$ e $\left.8 \mathrm{~L} \mathrm{~h}^{-1}\right)$ e quatro inclinações de terreno $(0,10,20$ e 30\%), com três repetições, totalizando em cada aplicação um volume de 2,17 L de água no solo. Passado uma hora das aplicações, amostras de solo deformadas eram coletadas, com um trado de rosca, para determinação da sua umidade. Com os dados de umidade, foram construídas as representações gráficas dos bulbos molhados e, através delas, observou-se que tanto a vazão do emissor quanto a inclinação do terreno influenciaram a geometria do bulbo úmido.
\end{abstract}

Palavras-chave: bulbo molhado, irrigação localizada, vazão

\section{ABSTRACT \\ SOIL MOISTURE DISTRIBUITION IN A SURFACE DRIP IRRIGATED SYSTEM WITH DIFFERENT GROUND INCLINATIONS}

Information on wet bulb geometry is important for the design and management of drip irrigation projects. There are several studies on the dimensions and characteristics of the wet bulb associating flow, application times and soil types, however literature still lacks sources regarding the behavior of irrigated land in regions with different slopes. Thus, the aim of this study was to evaluate the dimensions and characteristics of the wet bulb in surface drip irrigation in function of the drip flow and slope. The experiment was conducted at the Federal Institute Goiano - Câmpus Urutaí, in Urutaí, GO. In the study we adopted three flows (4, 5 and $\left.8 \mathrm{~L} \mathrm{~h}^{-1}\right)$ and four ground inclinations $(0,10,20$ and $30 \%)$, with three replications, totaling in each assessment a water volume of $2.17 \mathrm{~L}$ applied to the soil. After one hour of application, disturbed soil samples were collected with a screw auger to determine its moisture. With moisture data graphical representations of the wet bulbs were constructed, and from these it was observed that both the drip flow rate and the slope of the land influenced the wet bulb geometry.

Keywords: wet bulb, localized irrigation, flow

\section{Recebido para publicação em 06/12/2014. Aprovado em 31/03/2015.}

1 - Engenheiro Agrícola, Graduando em Matemática pela UFU/Uberlândia-MG, e-mail: aluiziodasilva@hotmail.com

2- Engenheiro Agrícola, Professor do IF Goiano/Urutaí-GO, e-mail: jose.antonio@ifgoiano.edu.br

3- Tecnólogo em Irrigação e Drenagem, e-mail: betocarvalho2014@gmail.com

4- Tecnólogo em Irrigação e Drenagem, e-mail: rafiwskbarcelos@hotmail.com

5- Licenciada em Química, Professora do IF Goiano/Urutaí-GO, e-mail: deboraastoni@yahoo.com.br 


\section{INTRODUÇÃO}

Diferentemente do crescimento populacional, os recursos naturais, dentre eles os hídricos, são finitos. E devido à crescente demanda por estes recursos, palavras como racionalidade, manejo e produtividade são ouvidas cada vez com mais freqüência (SALVADOR, 2014). Diante disso, a irrigação localizada oferece oportunidades para a otimização desses conceitos proporcionando melhorias no rendimento e eficiência da utilização da água, influenciando, positivamente, na qualidade da produção de alimentos (NOGUEIRA et al., 2000).

De acordo com Tolentino Junior et al. (2014), a irrigação localizada por gotejamento é uma das tecnologias que mais rapidamente vem se expandindo na moderna agricultura irrigada. Esta técnica de irrigação é caracterizada pela aplicação de pequenos volumes de água, em alta freqüência e diretamente na zona radicular das culturas, mantendo o solo próximo à capacidade de campo e evitando a perda de água por evaporação e percolação profunda (FRIZZONE et al., 2012). Esta aplicação resulta em um volume de solo molhado, conhecido como bulbo molhado ou úmido.

O conhecimento da distribuição da água no solo é de grande importância, tanto para o dimensionamento dos sistemas de irrigação como no seu manejo, pois a determinação do espaçamento entre emissores, número de emissores e taxa de evapotranspiração dependem de informações prévias acerca da movimentação de água no solo (KELLER; BLISNER, 1990; SOUZA; MATSURA, 2004). Os altos investimentos requeridos na implantação deste sistema de irrigação podem não fornecer retorno financeiro ao agricultor, caso não sejam utilizadas técnicas adequadas de manejo de irrigação que visem à racionalização do uso da água e o aumento da produtividade.

Neste sentido, diversos estudos têm sido desenvolvidos para determinação das dimensões e características do bulbo molhado associando vazões, tempos de funcionamento e tipos de solo (COELHO et al., 1995; NOGUEIRA et al., 2000; SOUZA; MATSURA, 2004; RIVERA, 2004; BARRETO et al., 2008; MAIA et al., 2010; LEVIEN et al., 2012; TOLENTINO JÚNIOR et al., 2014). Embora esteja claro que o raio (dimensão horizontal) seja favorecido pela capilaridade do solo, vazão do emissor, tempo de aplicação e capacidade de retenção de água no solo e que a profundidade molhada (dimensão vertical) seja dominada pela força gravitacional, ou seja, pela capacidade de drenagem do solo, estas relações não estão claramente estudadas quando associadas a diferentes inclinações do terreno. Isso pode resultar em bulbos úmidos com características geométricas bastante distintas quando comparadas com o solo sem declividade.

No Brasil, são consideradas Áreas de Preservação Permanente (APP), logo, não cultiváveis, as encostas ou partes destas com declividade superior a $45^{\circ}$, equivalente a $100 \%$ na linha de maior declive, e, topo de morros, montes, montanhas e serras, com altura mínima de 100 metros e inclinação média maior que $25^{\circ}(47 \%)$, nas áreas delimitadas a partir da curva de nível correspondente a dois terços da altura mínima da elevação, sempre em relação à base, sendo esta definida pelo plano horizontal determinado por planície ou espelho d'água adjacente ou, nos relevos ondulados, pela cota do ponto de sela mais próximo da elevação (BRASIL, 2012).

Observando-se, então, a existência, perante a lei, de terras agricultáveis em regiões que apresentam valores não muito restritos de declividade, objetivou-se neste estudo avaliar as dimensões e características do bulbo molhado na irrigação por gotejamento superficial em função da vazão do emissor e da inclinação do terreno.

\section{MATERIAL E MÉTODOS}

O experimento foi conduzido no Instituto Federal Goiano - Câmpus Urutaí, em Urutaí, estado de Goiás, Brasil, localizado a $17^{\circ} 29^{\prime} 6$ 'S, $48^{\circ} 12$ '27'O e altitude de $712 \mathrm{~m}$, no período de fevereiro a julho de 2014. Segundo a classificação de Köppen, o clima da região é do tipo $\mathrm{Cwa}$, caracterizado como úmido tropical com inverno seco e verão chuvoso, com precipitação e temperatura médias, anuais, de $2000 \mathrm{~mm}$ e $28^{\circ} \mathrm{C}$.

O sistema de irrigação localizada captava água do córrego Palmital e contava com gotejadores autocompensantes de 4, 5 e $8 \mathrm{~L} \mathrm{~h}^{-1}$, montado de forma a permitir o posicionamento das linhas de emissão, cada qual com três gotejadores (três repetições), sobre as diferentes inclinações estudadas, sendo elas: $0,10,20$ e $30 \%$; valores que correspondem em graus a $0,5,71,11,31$ e 16,7, respectivamente. Nas áreas que apresentavam declividade, as linhas de emissão foram montadas 
perpendicularmente ao declive.

O tempo de funcionamento do sistema em cada aplicação foi baseado na cultura do tomate, estágio final, com coeficiente de cultivo $(\mathrm{Kc})$ no valor de 1,10 (SANTANA et al., 2011), considerando a reposição de uma taxa de evapotranspiração média de 5,40 $\mathrm{mm} \mathrm{dia}{ }^{-1}$ (BERNARDO et al., 2006), turno de rega de dois dias, porcentagem da área molhada de 40\% (KELLER; BLISNER, 1990), espaçamento da cultura de 1 x 0,4 m (MACEDO et al., 2005) e adotando uma eficiência de aplicação média de 90\% característica para sistemas localizados. Dessa forma, os tempos de irrigação para as vazões de 4,5 e $8 \mathrm{~L} \mathrm{~h}^{-1}$ foram, respectivamente, de 32, 26 e $16 \mathrm{~min}$, totalizando, em cada aplicação, um volume de 2,17 L.

Para determinação da umidade do solo após as aplicações, amostras de solo deformadas foram retiradas, uma hora depois do término da aplicação, com um trado de rosca. Esta amostragem foi realizada de forma a cobrir todo o perfil do bulbo molhado, tanto no plano horizontal (superfície) como no vertical (profundidade), formandose uma malha quadriculada. Para tal, no plano horizontal, adotou-se um espaçamento de $10 \mathrm{~cm}$ e no vertical um espaçamento de $15 \mathrm{~cm}$, tendo-se como referência o ponto de emissão do gotejador.

Após a retirada, as amostras foram acondicionadas em cápsulas metálicas de $113 \mathrm{~cm}^{3}$, com tampa para evitar a evaporação da água, e conduzidas ao Laboratório de Pesquisa e Análises Químicas, do Instituto Federal Goiano - Câmpus Urutaí. No laboratório as amostras úmidas foram pesadas e secas em estufa a $105^{\circ} \mathrm{C}$ até atingirem massa constante e, depois de secas, pesadas novamente. Com isso, determinou-se a umidade de cada amostra dividindo-se a massa de água inicial pela massa de solo seco e multiplicando-se o valor por 100 para obtenção da umidade gravimétrica em porcentagem, conforme Embrapa (2011).

Com os valores de umidade, foram geradas as representações gráficas dos bulbos molhados com vistas na superfície do solo, ao longo da linha de emissão e perpendicularmente à linha de emissão com os valores médios das três repetições.

Para determinação de parâmetros físicos do solo estudado, foram retiradas amostras de solo deformadas e indeformadas do local de experimentação e levadas ao Laboratório de Física dos Solos, do Instituto Federal Goiano - Câmpus Urutaí, para obtenção dos índices de densidades do solo e de partículas, porosidade total e classe textural. conforme metodologias sugeridas pela Embrapa (2011). Os resultados estão apresentados no Quadro 1.

\section{RESULTADOS E DISCUSSÃO}

Na Figura 1 estão apresentadas as isolinhas de umidade dos bulbos molhados formados pelos gotejadores aplicando vazão de $4 \mathrm{~L} \mathrm{~h}^{-1}$ e tomando como referência o ponto de emissão do gotejador.

$\mathrm{Na}$ Figura 2 estão apresentadas as isolinhas de umidade dos bulbos molhados formados pelos gotejadores aplicando vazão de $5 \mathrm{~L} \mathrm{~h}^{-1}$ e tomando como referência o ponto de emissão do gotejador.

$\mathrm{Na}$ Figura 3 estão apresentadas as isolinhas de umidade dos bulbos molhados formados pelos gotejadores aplicando vazão de $8 \mathrm{~L} \mathrm{~h}^{-1}$ e tomando como referência o ponto de emissão do gotejador.

Quadro 1. Densidade do solo ( $\rho s)$, porosidade total $(\mathrm{N})$ e classe textural para diferentes profundidades do solo.

\begin{tabular}{ccccccc}
\hline Profundidade $(\mathrm{cm})$ & $\rho \mathrm{s}\left(\mathrm{g} \mathrm{cm}^{-3}\right)$ & $\mathrm{N}\left(\mathrm{cm}^{3} \mathrm{~cm}^{-3}\right)$ & Areia $\left(\mathrm{g} \mathrm{kg}^{-1}\right)$ & Silte $\left(\mathrm{g} \mathrm{kg}^{-1}\right)$ & Argila $\left(\mathrm{g} \mathrm{kg}^{-1}\right)$ & Classe textural \\
\hline $0-5$ & 1,40 & 0,45 & 613 & 189 & 198 & Franco Arenosa \\
$5-15$ & 1,33 & 0,49 & 577 & 187 & 236 & Franca \\
$15-30$ & 1,30 & 0,49 & 563 & 162 & 275 & Franca \\
$30-45$ & 1,25 & 0,51 & 536 & 113 & 351 & Franco Argilosa \\
$45-60$ & 1,24 & 0,55 & 518 & 120 & 362 & Franco Argilosa \\
$60-75$ & 1,34 & 0,50 & 535 & 133 & 332 & Franco Argilosa \\
\hline
\end{tabular}


A.
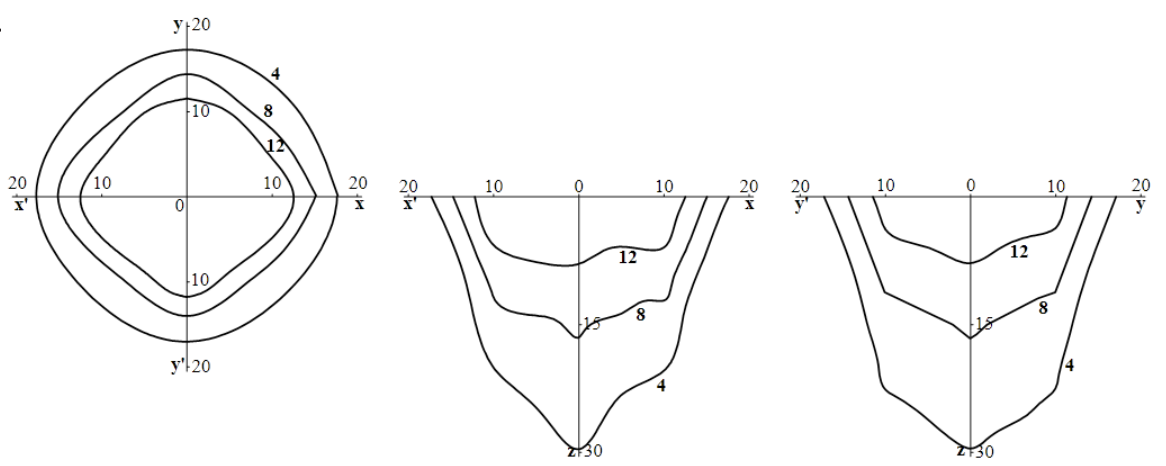

B.
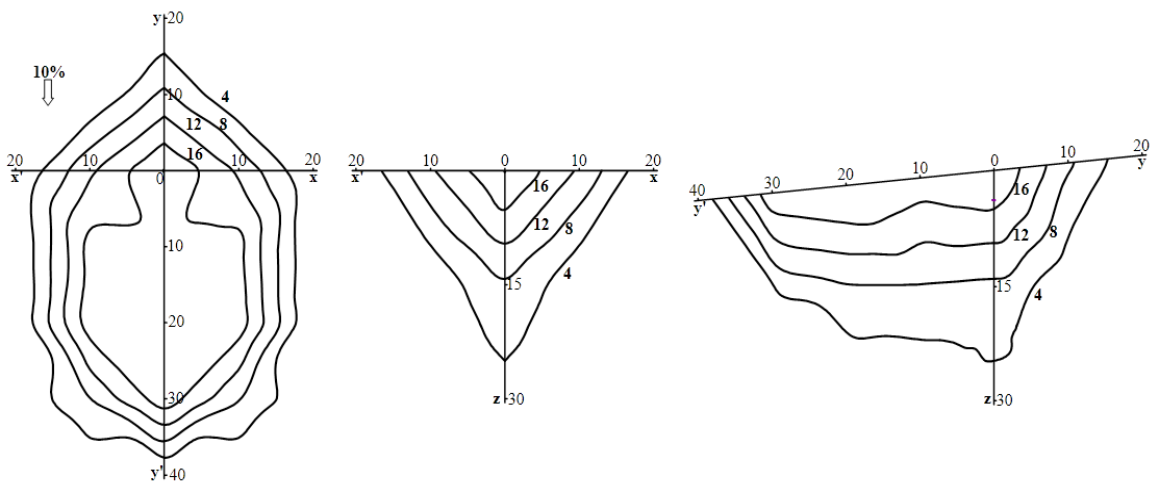

C.
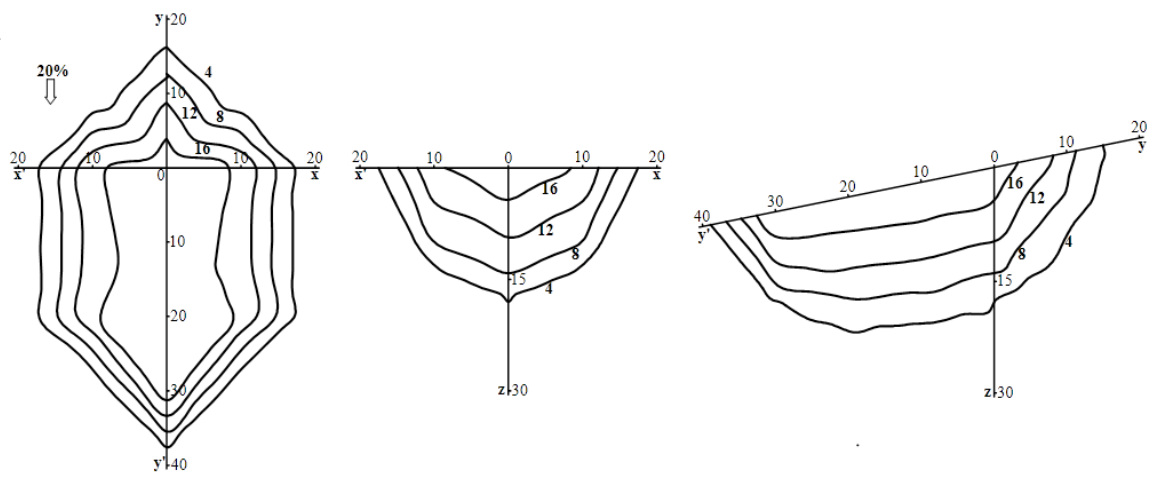

D.
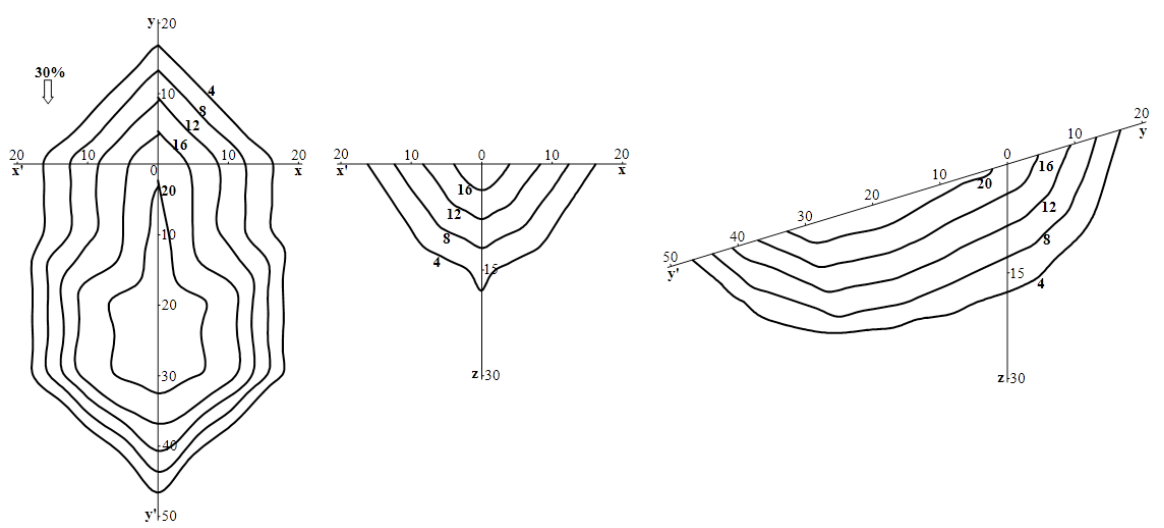

Figura 1. Isolinhas de umidade gravimétrica em porcentagem mostrando a distribuição de água pelo bulbo molhado na superfície do solo (plano x-y), ao longo da linha de emissão (plano x-z) e perpendicularmente à linha de emissão (plano y-z), para a vazão de $4 \mathrm{~L} \mathrm{~h}^{-1}$, nas inclinações de: A) $0 \%$, B) $10 \%$, C) $20 \%$ e D) $30 \%$. Em que os eixos estão cotados em centímetros e z a profundidade.

\section{REVENG}


A.

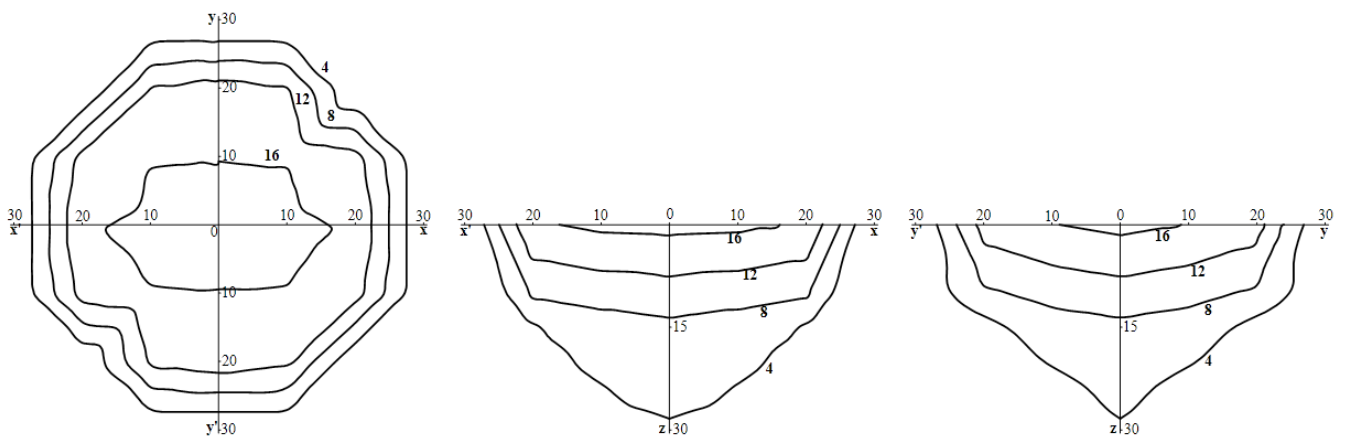

B.
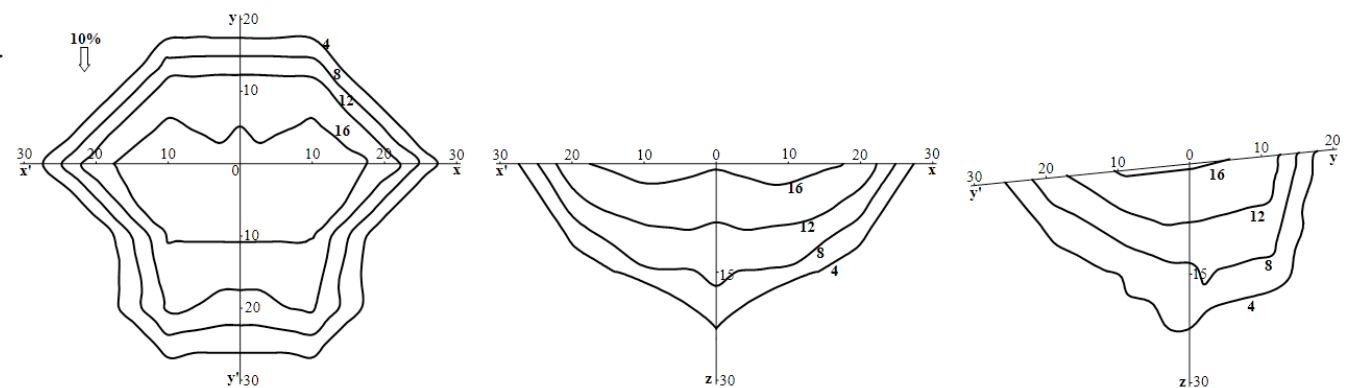

C.
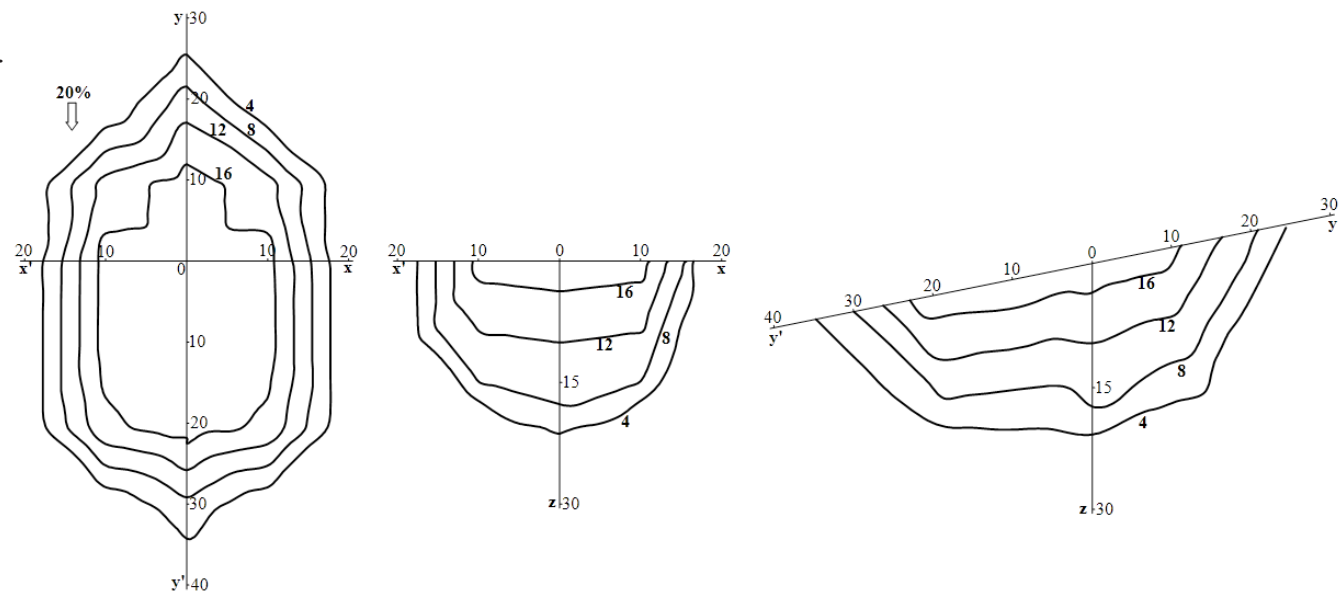

D.
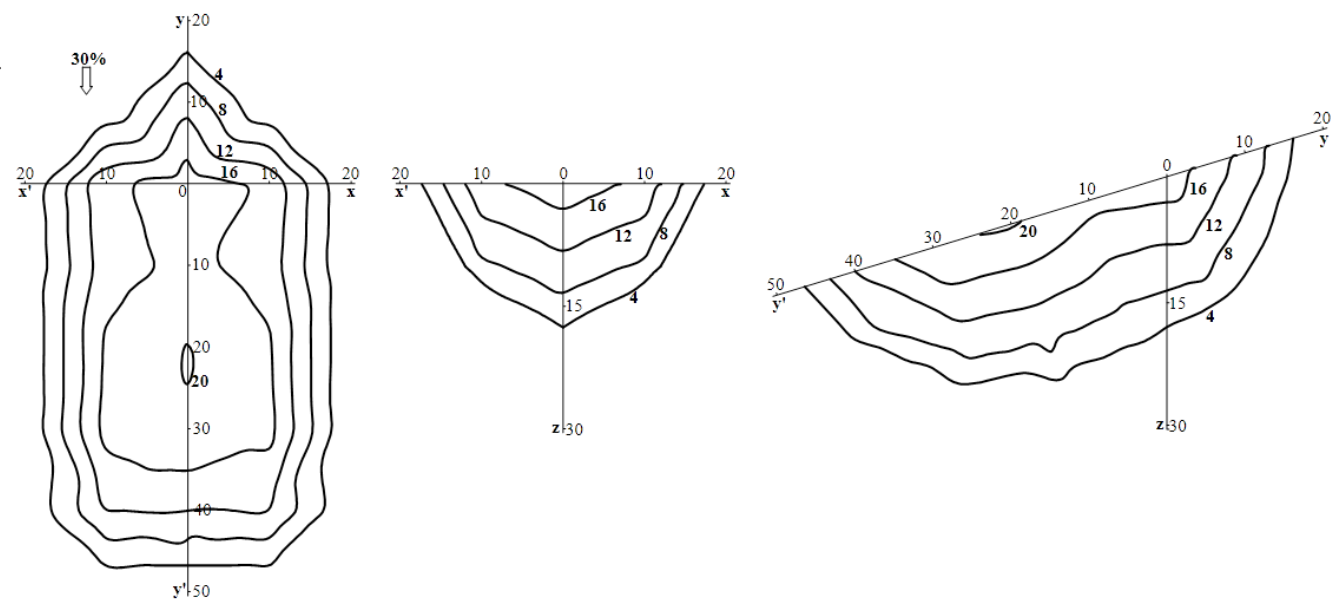

Figura 2. Isolinhas de umidade gravimétrica em porcentagem mostrando a distribuição de água pelo bulbo molhado na superfície do solo (plano x-y), ao longo da linha de emissão (plano x-z) e perpendicularmente à linha de emissão (plano y-z), para a vazão de $5 \mathrm{~L} \mathrm{~h}^{-1}$, nas inclinações de: A) $0 \%$, B) $10 \%$, C) $20 \%$ e D) $30 \%$. Em que os eixos estão cotados em centímetros e z a profundidade. 
A.

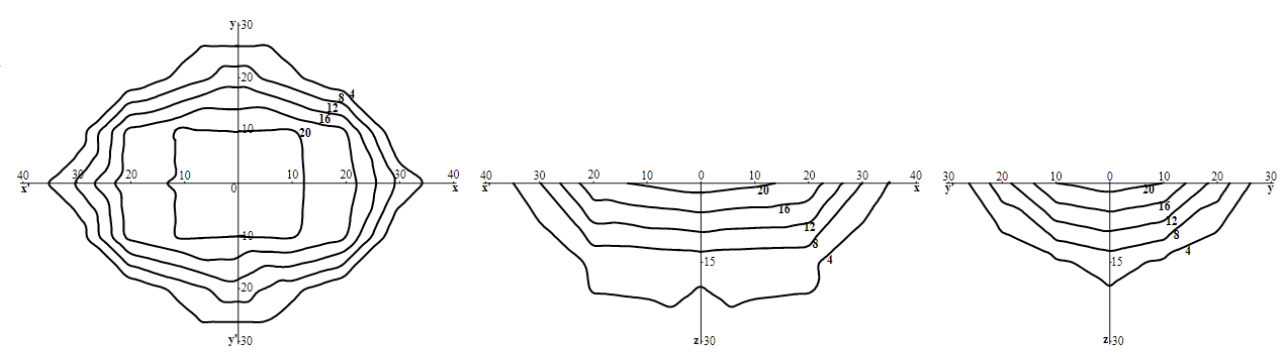

B.
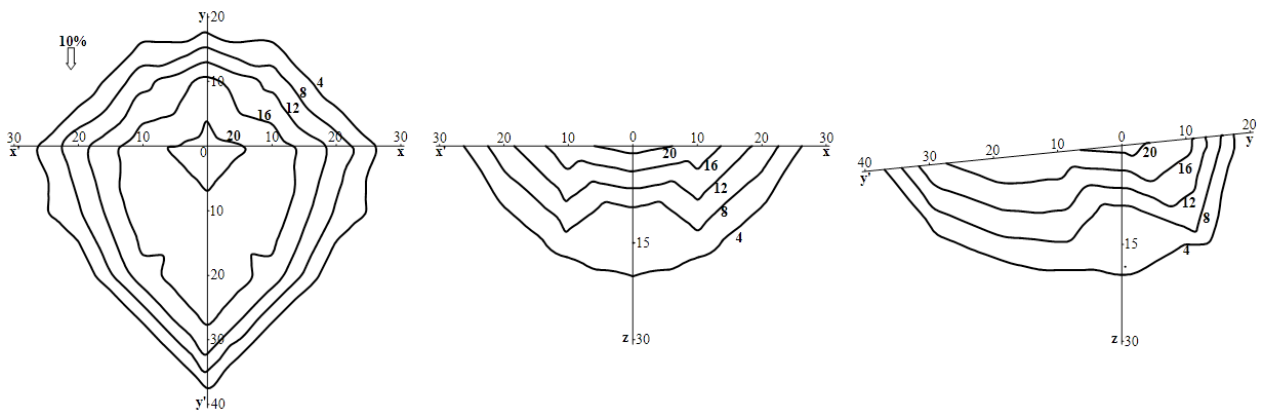

C.
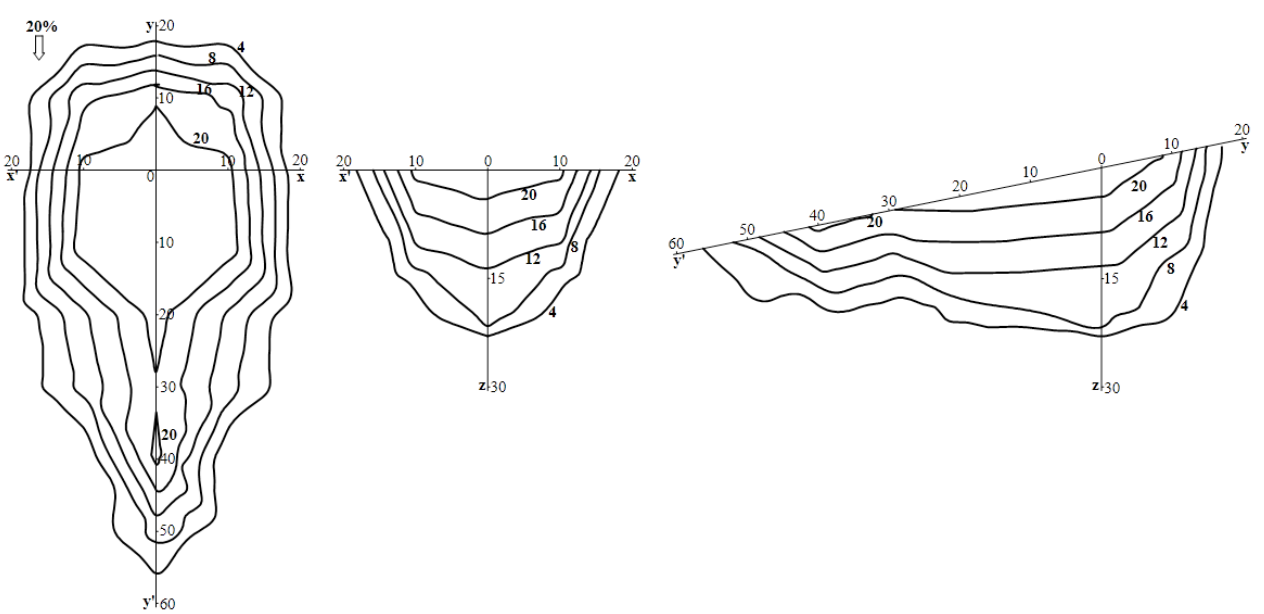

D.
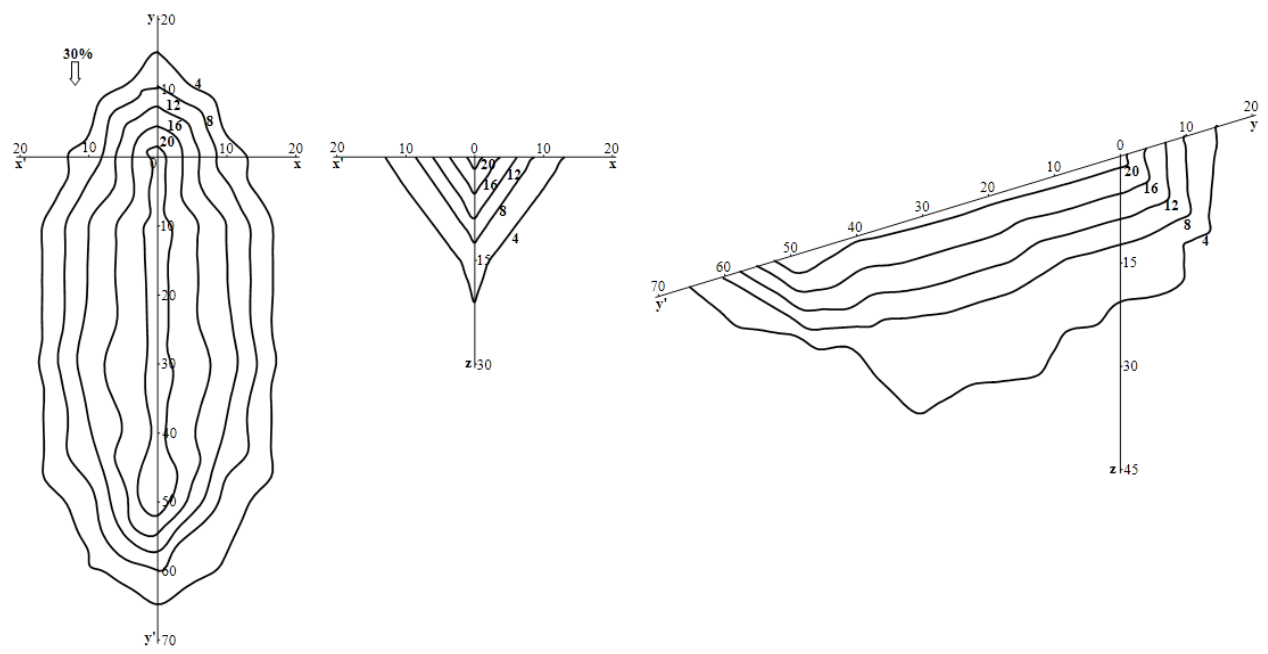

Figura 3. Isolinhas de umidade gravimétrica em porcentagem mostrando a distribuição de água pelo bulbo molhado na superfície do solo (plano x-y), ao longo da linha de emissão (plano x-z) e perpendicularmente à linha de emissão (plano y-z), para a vazão de $8 \mathrm{~L} \mathrm{~h}^{-1}$, nas inclinações de: A) $0 \%$, B) $10 \%$, C) $20 \%$ e D) $30 \%$. Em que os eixos estão cotados em centímetros e z a profundidade. 
Pelas Figuras 1, 2 e 3, observa-se que a inclinação afetou o comportamento da distribuição de água no solo, sendo que, quanto maior a inclinação do terreno maior a tendência de deslocamento da frente de molhamento do bulbo no sentido da declividade. Barreto et al. (2008), fazendo a avaliação do bulbo úmido por múltiplos cortes em trincheira, também notaram a tendência de desenvolvimento da região úmida seguindo o declive do terreno.

Observou-se, também, que, quanto maior a vazão, maior migração radial da água na superfície do solo, formando bulbos mais abertos. Por outro lado, quanto maior a vazão e a inclinação, menores foram os valores de profundidade alcançados pela água, o que pode ser explicado devido ao fato de a água tender a se deslocar na superfície do solo antes de começar o processo de infiltraçãopercolação. Os valores das isolinhas de umidade variaram de 4 a $20 \%$, onde as maiores porcentagens se concentraram próximo aos pontos de emissão, exceto nas Figuras 1D e 2D.

Analisando as Figuras 1A e 2A, tem-se que o raio do bulbo foi inferior a sua profundidade, fato semelhante também observado por Souza et al. (2007). Já na Figura 3A houve o predomínio radial sobre o vertical, semelhante ao observado por Maia et al. (2010), autores que salientam que a taxa de aplicação de alguns emissores pode ser superior à capacidade de infiltração de água no solo, o que, conseqüentemente, tenderá a formar bulbos com maior largura superficial e menor profundidade, resultado que também está em concordância com experimentos realizados por Souza e Matsura (2004). Outro fator importante foi que, ao decorrer do teste de campo, percebeu-se a formação de uma fina crosta embaixo do gotejador, possivelmente pela dispersão de partículas durante a aplicação da água, que pode estar relacionado à maior vazão do emissor, ocasionando a redução da porosidade e, conseqüentemente, da condutividade hidráulica do solo, indo de encontro a resultados obtidos por Rivera (2004).

Na Figura 1A observa-se que a distância radial alcançada pelo bulbo molhado na superfície foi de $18 \mathrm{~cm}$, sendo que Rivera (2004) e Nogueira et al. (2000), fazendo aplicação de água via gotejamento superficial, notaram valores radiais de 35 e $25 \mathrm{~cm}$, respectivamente. Diferença devido ao volume aplicado e ao tempo de espera para coleta das amostras, 2,17 L e $1 \mathrm{~h}$ nesta pesquisa, contra $6 \mathrm{~L}$, $4,33 \mathrm{~L}$ e $24 \mathrm{~h}$ naquelas. Ainda na mesma figura, a profundidade máxima alcançada foi de $30 \mathrm{~cm}$, enquanto que, Barros et al. (2009), aplicando um volume de $3 \mathrm{~L}$ de água via irrigação por gotejamento superficial, com um emissor de vazão $4 \mathrm{~L} \mathrm{~h}^{-1} \mathrm{em}$ um Nitossolo Vermelho, obtiveram como profundidade o valor de $18 \mathrm{~cm}$, contraste causado, provavelmente, pelo maior teor de argila nesse tipo de solo.

Maia et al. (2010), estudando as dimensões do bulbo molhado na irrigação por gotejamento superficial, fazendo a aplicação de água em quatro tempos diferentes $(1,2,4$ e $7 \mathrm{~h})$, dentro de quatro vazões distintas $\left(1,2,4\right.$ e $\left.8 \mathrm{~L} \mathrm{~h}^{-1}\right)$ em um Neossolo Quartizarênico, verificaram que o diâmetro máximo do bulbo na superfície foi inferior a 60 $\mathrm{cm}$ no tempo de $1 \mathrm{~h}$ de aplicação. Resultados que se opõem aos obtidos nesta pesquisa, pois, todos os tempos de aplicação foram inferiores a $1 \mathrm{~h}(16,26$ e $32 \mathrm{~min})$ e, em todas as inclinações de $30 \%$, por exemplo, observou-se um diâmetro superficial máximo superior a $60 \mathrm{~cm}$. Diferença que pode ser explicada pela topografia do local da experimentação, enquanto naquele o terreno era plano, neste havia as inclinações, evidenciando a importância da declividade nas dimensões do bulbo molhado.

A maior profundidade alcançada pela água nas aplicações ocorreu na vazão de $4 \mathrm{~L} \mathrm{~h}^{-1} \mathrm{e}$ inclinação de $0 \%$ (Figura 1A), chegando ao valor de $30 \mathrm{~cm}$, sendo que, de acordo com Bernardo et al. (2006), a profundidade efetiva do sistema radicular da cultura do tomate é, de modo geral, de $40 \mathrm{~cm}$. Concluindo, mesmo na aplicação que alcançou profundidade maior, $30 \mathrm{~cm}$, não haveria, caso a cultura do tomate estivesse implantada, perda de água por percolação profunda.

\section{CONCLUSÕES}

- Para as condições de estudo, as diferentes inclinações do terreno e vazões dos gotejadores influenciaram a geometria do bulbo molhado e a distribuição de umidade na sua região, evidenciando a importância do relevo no posicionamento dos emissores na irrigação por gotejamento superficial. 


\section{REFERÊNCIAS BIBLIOGRÁFICAS}

BARRETO, C.V.G.; SAKAI, E.; PIRES, R.C.M.; ARRUDA, F.B. Técnica de avaliação de bulbo úmido por múltiplos cortes em trincheira. Irriga, Botucatu, v.13, n.2, p. 160-169, 2008. Disponível em: $\quad<$ http://200.145.140.50/ojs1/viewarticle. php?id=317\&layout=abstract $>$. Acesso em: 16 nov. 2014.

BARROS, A.C.; FOLEGATTI, M.V.; SOUZA, C.F.; SANTORO, B.L. Distribuição de água no solo aplicado por gotejamento enterrado e superficial. Revista Brasileira de Engenharia Agrícola e Ambiental, Campina Grande, v.13, n.6, p.700-707, 2009. Disponível em: $<\underline{\text { http://dx.doi.org/10.1590/ }}$

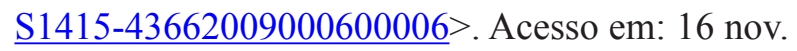
2014.

BERNARDO, S.; SOARES, A.A.; MANTOVANI, E.C. Manual de irrigação. 8ed. Viçosa: UFV/ Imprensa Universitária, 2006. 625p.

BRASIL. Lei $\mathrm{n}^{\circ}$ 12.651, de 25 de maio de 2012. Dispõe sobre a proteção da vegetação nativa; altera as Leis $n^{\circ} 6.938$, de 31 de agosto de 1981, 9.393, de 19 de dezembro de 1996, e 11.428 , de 22 de dezembro de 2006; revoga as Leis $n^{\circ} 4.771$, de 15 de setembro de 1965, e 7.754, de abril de 1989, e a Medida Provisória ${ }^{\circ}$ 2.166-67, de 24 de agosto de 2001; e dá outras providências. Casa civil: Subchefia para assuntos jurídicos. Disponível em: $<$ http://www.planalto.gov.br/ccivil_03/ ato20112014/2012/lei/112651.htm>. Acesso em: 16 nov. 2014.

COELHO, E.F.; OR, D.; ANDRADE, C.L.T. Avaliação de regime permanente em irrigação por gotejamento e posicionamento de sensores de umidade e de potencial matricial no bulbo molhado. Pesquisa Agropecuária Brasileira, Brasília, v.30, n.11, p.1327-1333, 1995. Disponível em: $<\underline{\text { http:// }}$ ainfo.cnptia.embrapa.br/digital/bitstream/AISEDE/3219/1/pab95 07 nov.pdf $>$. Acesso em: 16 nov. 2014.

EMBRAPA - Empresa brasileira de pesquisa Agropecuária. Centro Nacional de Pesquisa de
Solos. Manual de métodos de análise de solos. 2ed. Rio de Janeiro, 2011. 225p.

FRIZZONE, J.A.; FREITAS, P.S.L.; REZENDE, R.; FARIA, M.A. Microirrigação: Gotejamento e Microaspersão. Maringá, PR: Eduem, 2012. 356p. KELLER, J.; BLIESNER, R.D. Sprinkle and trickle irrigation. New York: AVI Book, 1990. 640p.

LEVIEN, S.L.A.; MIRANDA, J.H.; BEZERRA, A.H.F. Estimativa de dimensões de volume de solo molhado na irrigação por gotejamento superficial em solo de textura média: condição inicial do solo. Revista Brasileira de Agricultura Irrigada, Fortaleza, v.6, n.2, p.127-135, 2012. Disponível em: $\quad<$ http://www.inovagri.org.br/revista/index. php/rbai/article/view/112/pdf 99>. Acesso em: 16 nov. 2014.

MACEDO, J.R.; CAPACHE, C.L.; MELO, A.S.; BHERING, S.B. Recomendações técnicas para a produção do tomate ecologicamente cultivado TOMATEC. Rio de Janeiro, RJ: Embrapa Solos, 2005. 10p. (Embrapa Solos. Circular Técnica, 33). Disponível em: <http://ainfo.cnptia.embrapa.br/ digital/bitstream/item/84070/1/circulartecnica-33tomatec.pdf $>$. Acesso em: 16 nov. 2014.

MAIA, C.E.; LEVIEN, S.L.A.; MEDEIROS, J.F.; DANTAS NETO, J. Dimensões de bulbo molhado na irrigação por gotejamento superficial. Revista Ciência Agronômica, Fortaleza, v.41, n.1, p.149-158, 2010. Disponível em: <http://www. ccarevista.ufc.br/seer/index.php/ccarevista/article/ view/531/419>. Acesso em: 16 nov. 2014.

NOGUEIRA, C.C.P.; COELHO, E.F.; LEÃO, M.C.S. Características e dimensões do volume de um solo molhado sob gotejamento superficial e subsuperficial. Revista Brasileira de Engenharia Agrícola e Ambiental, Campina Grande, v.4, n.3, p.315-320, 2000. Disponível em: <http:// dx.doi.org/10.1590/S1415-43662000000300001>. Acesso em: 16 nov. 2014.

RIVERA, R.N.C. Modelagem da dinâmica da água e do potássio na irrigação por gotejamento 
superficial. 2004. 106p. Tese (Doutorado em Agronomia) - Escola Superior de Agricultura "Luiz de Queiroz", Universidade de São Paulo, Piracicaba, SP, 2004. Disponível em: <http://www.teses.usp.br/ teses/disponiveis/11/11143/tde-26042005-140149/ pt-br.php>. Acesso em: 06 dez. 2014.

SALVADOR, C.A. Desenvolvimento e avaliação de um sistema de controle de nitrato em soluções nutritivas. 2014. 105p. Tese (Doutorado em Agronomia) - Escola Superior de Agricultura "Luiz de Queiroz", Universidade de São Paulo, Piracicaba, SP, 2014. Disponível em: <http:// www.teses.usp.br/teses/disponiveis/11/11143/tde13022014-083519/pt-br.php>. Acesso em: 06 dez. 2014.

SANTANA, M.J.; PEREIRA, U.C.; BEIRIGO, J.D.C; SOUZA, S.S.; CAMPOS, T.L.; VIEIRA, T.A. Coeficientes de cultura para o tomateiro irrigado. Irriga, Botucatu, v.16, n.1, p.11-20, 2011. Disponível em: $<$ http://irriga.fca.unesp.br/index. php/irriga/article/view/187/96>. Acesso em: 16 nov. 2014.
SOUZA, C.F.; MATSURA, E.E. Distribuição da água no solo para o dimensionamento da irrigação porgotejamento. Revista Brasileira de Engenharia Agrícola e Ambiental, Campina Grande, v.8, n.1, p.7-15, 2004. Disponível em: <http://dx.doi. org/10.1590/S1415-43662004000100002>. Acesso em: 16 nov. 2014.

SOUZA, E.A.; COELHO, E.F.; PAZ, V.P.S. Distribuição da umidade num perfil de solo irrigado por gotejamento superficial e subsuperficial. Ciência e Agrotecnologia, Lavras, v.31, n.4, p.1161-1166, 2007. Disponível em: $<$ http:// dx.doi.org/10.1590/S1413-70542007000400032>. Acesso em: 16 nov. 2014.

TOLENTINO JÚNIOR, J.B.; MARINHO, L.B.; SOUZA, C.F.; FRIZZONE, J.A. Desenvolvimento de um modelo numérico para modelagem do bulbo molhado em irrigação por gotejamento. Irriga, Botucatu, edição especial 1, p.11-20, 2014. Disponível em: $<$ http://irriga.fca.unesp.br/index. php/irriga/article/view/1696/954>. Acesso em: 16 nov. 2014. 